Diego Armando Coello-Paute; Juan Carlos Erazo-Álvarez; Cecilia Ivonne Narváez-Zurita; Juan Edmundo Álvarez-Gavilanes

http://dx.doi.org/10.35381/r.k.v5i3.895

\title{
Capital intelectual como herramienta de gestión del conocimiento en cooperativa de ahorro y crédito
}

\section{Intellectual capital as a knowledge management tool in a savings and credit cooperative}

\author{
Diego Armando Coello-Paute \\ diego.coello@psg.ucacue.edu.ec \\ Universidad Católica de Cuenca, Cuenca \\ Ecuador \\ https://orcid.org/0000-0002-3442-6996 \\ Juan Carlos Erazo-Álvarez \\ icerazo@psg.ucacue.edu.ec \\ Universidad Católica de Cuenca, Cuenca \\ Ecuador \\ https://orcid.org/0000-0001-6480-2270 \\ Cecilia Ivonne Narváez-Zurita \\ inarvaez@ucacue.edu.ec \\ Universidad Católica de Cuenca, Cuenca \\ Ecuador \\ https://orcid.org/0000-0002-7437-9880 \\ Juan Edmundo Álvarez-Gavilanes \\ juan.alvarezg@ucacue.edu.ec \\ Universidad Católica de Cuenca, Cuenca \\ Ecuador \\ https://orcid.org/0000-0003-0978-3235
}

Recibido: 20 de mayo de 2020

Revisado: 15 de junio de 2020

Aprobado: 30 de julio de 2020

Publicado: 15 de agosto de 2020 
Diego Armando Coello-Paute; Juan Carlos Erazo-Álvarez; Cecilia Ivonne Narváez-Zurita; Juan Edmundo Álvarez-Gavilanes

\title{
RESUMEN
}

El objetivo de investigación se fundamenta en analizar el capital intelectual como herramienta de gestión del conocimiento en cooperativa de ahorro y crédito Erco Ltda. Fue de alcance descriptivo de carácter transversal, el universo poblacional estuvo conformado por un total de 143 colaboradores administrativos, servicio directo con el cliente. La cooperativa de ahorro y crédito Erco Ltda. cuenta con un plan de capacitaciones, sin embargo, este no es de conocimiento de sus empleados, lo cual recae en la falta de preparación de herramientas tecnológicas y una planificación clara del impacto productivo que puede acarrear. Ante los grandes cambios que tiene la cooperativa en la actualidad los funcionarios deben desarrollar nuevas habilidades como destrezas para poder adaptarse a estos cambios tecnológicos y de innovación, pero estas habilidades deben ser desarrolladas con una correcta inversión realizada por el mando jerárquico superior a todas sus alas del negocio.

Descriptores: Recursos humanos; desarrollo de recursos humanos; gestión del personal; formación. (Palabras tomadas del Tesauro UNESCO).

\begin{abstract}
The research objective is based on analyzing intellectual capital as a knowledge management tool in the savings and credit cooperative Erco Ltda. It was descriptive in scope of a transversal nature, the population universe was made up of a total of 143 administrative collaborators, direct service with the client. The savings and credit cooperative Erco Ltda. Has a training plan, however, this is not known to its employees, which is due to the lack of preparation of technological tools and a clear planning of the productive impact that it may have. Faced with the great changes that the cooperative is currently experiencing, officials must develop new skills as skills to be able to adapt to these technological and innovation changes, but these skills must be developed with a correct investment made by the hierarchical command superior to all its wings. of the business.
\end{abstract}

Descriptors: Human resources; human resources development; personnel management; training. (Words taken from the UNESCO Thesaurus). 
Revista Arbitrada Interdisciplinaria KOINONIA

Año 2020. Vol V. N³. Especial: Administración

Hecho el depósito de Ley: FA2016000010

ISSN: 2542-3088

FUNDACIÓN KOINONIA (F.K). Santa Ana de Coro. Venezuela.

\section{Diego Armando Coello-Paute; Juan Carlos Erazo-Álvarez; Cecilia Ivonne Narváez-Zurita;} Juan Edmundo Álvarez-Gavilanes

\section{INTRODUCCIÓN}

El impulso económico de las de las instituciones del sector popular y solidario como incentivo estatal se establece en el año 1937 mediante la promulgación de leyes que ayuden a impulsar la economía, y mejorar la calidad de vida de la sociedad. En este año se da a conocer la primera ley del cooperativismo que mostraba a las cooperativas de ahorro y crédito y producción en busca de generar desarrollo productivo como igualdad económica. La ley de cooperativas fue modificada por varias ocasiones hasta encontrar una ley correcta. A través de una resolución la junta de regulación política monetaria financiera determina que las cooperativas son abiertas a la sociedad en general, y que su ente regulador será la Súper de Bancos y Seguros y las no contempladas por este ente de control serán reguladas por la Dirección Nacional de Cooperativas.

En el año 2012, la Superintendencia de Bancos (SB) monitoreaba y examinaba a las cooperativas de ahorro y crédito y una caja, para tener un control efectivo de la parte financiera, La Súper intendencia de economía popular y solidaria, "SEPS", concluyo que las cooperativas de ahorro y crédito deben contar con un estatuto que permita tener una regulación por parte de los organismos de control, por el año 2013 se cuenta con un informe cuantitativo con un total de 946 cooperativas del sector popular y solidario, Para poder realizar un control adecuado, las instituciones financieras de la economía popular y solidaria fueron calificadas en cuatro segmentos, siendo el primer segmento el más fuerte del mercado financiero superando los 80 millones de dólares, por tal motivo el tamaño de las instituciones financieras de la economía popular y solidaria es medido por sus activos, cuyo activo principal es su cartera de crédito.

En la actualidad las cooperativas son entendidas por sociedad de personas con gestión democrática y personalidad jurídica de derecho privado e interés social, las cooperativas de ahorro y crédito buscan incentivar la economía mediante la intermediación financiera, en zonas en las cuales no llegan los servicios financieros creando oportunidades de crecimiento a sus socios, brindando fuentes de empleo a sus habitantes. Con la información disponible se pudo evidenciar que las cooperativas de ahorro y crédito se 


\section{Diego Armando Coello-Paute; Juan Carlos Erazo-Álvarez; Cecilia Ivonne Narváez-Zurita;} Juan Edmundo Álvarez-Gavilanes

encuentran localizadas en las principales provincias como son Pichincha, Tungurahua, Chimborazo, Cotopaxi, Guayas, Loja y Azuay (Superintendicia de Economia Popular y Solidaria, 2018).

Es así como un 21 de octubre de 1964 se funda la Cooperativa de Ahorro y Crédito "ERCO" Ltda. En el año 2001 "ERCO" Itda extiende sus servicios a la comunidad en general, apertura sus primeras agencias ubicadas en Azuay Cañar y Morona Santiago, en el año 2013, logra expandirse hacia la provincia del Guayas, por el año 2018 ya cuenta con agencias en la Provincia de El Oro, Loja y Zamora Chinchipe, estando en las principales provincias del país con 30 oficinas, con el crecimiento rápido se ha realizado contrataciones y vinculaciones de personal que no cuentan con conocimientos suficientes en diferentes departamentos y áreas de influencia, dificultando así tener funcionarios capacitados en puestos de gran impacto en el desarrollo productivo y financiero de la cooperativa.

La falta de capacitaciones en áreas estratégicas, la vinculación y contratación inadecuada de personal que no está acorde al giro del negocio, el hacer contrataciones basándose en recomendaciones de amistad en los procesos preestablecidos, tomándose decisiones inadecuadas, realizando contratos de personal sin capacidad ni experiencia crean conflictos que afectan el desarrollo intelectual, ocasionan detener los procesos y dificultan tomar decisiones adecuadas impidiendo el cumplimiento de objetivos institucionales planificados en el inicio del periodo, esto acarrea consecuencias en el corto plazo que afectan directamente en el desarrollo productivo, a la cooperativa le toma más tiempo y recursos capacitar a empleados sin experiencia que tener una contratación acorde al perfil requerido y al título de perfil de carrera, dicha contratación inadecuada conlleva a tener pérdidas de tiempo como de recursos al tratar de involucrar a una persona sin el entrenamiento necesario para ocupar un cargo determinado, por lo antes expuesto este documento determinara lo importante que es hacer planes de contratación claros y verídicos que deben tener las mejores competencias, en busca de mejorar la calidad de los colaboradores que ayuden a medir la verdadera contribución de un 


\section{Diego Armando Coello-Paute; Juan Carlos Erazo-Álvarez; Cecilia Ivonne Narváez-Zurita; Juan Edmundo Álvarez-Gavilanes}

empleado hacia la institución y de qué manera conlleva al cumplimiento de objetivos departamentales planificados en un periodo contable que son evaluados por las destrezas, conocimientos y la actitud en la toma de decisiones, orientando a que los colaboradores ya existentes y los que sean incorporados a la institución tenga el entrenamiento necesario para hacer frente a las necesidades del puesto (Cooperativa de Ahorro y Credito Erco, 2019).

En función de lo expuesto, el objetivo de investigación se fundamenta en analizar el capital intelectual como herramienta de gestión del conocimiento en cooperativa de ahorro y crédito Erco Ltda.

\section{Referencial teórico}

\section{El capital intelectual como herramienta de gestión de conocimiento}

En este sentido, (Bueno, et al., 2008), indican que el Euroforum, 1998 establece que los activos intangibles de una organización es el capital intelectual, que a pesar de no estar registrados en los libros contables son los que crean el valor actual de una organización y su valor a largo plazo, que incluye al capital humano como herramienta de conocimientos, habilidades, aptitudes y destrezas del personal el mismo que no puede ser calificados pero que marca la diferencia de una organización en el mercado, una empresa se compone de capital estructural que tiene conocimientos adquiridos y desarrollados por las empresas más su capacidad de innovación en el tiempo.

El capital intelectual está vinculado con la evaluación de los activos intangibles conocimientos y por ende, es una cuenta del activo que no se pude identificar. La capacidad de las personas son la clave de las organizaciones y el prestigio de sus empleados, el know-how de la empresa que es el conjunto de conocimientos administrativos y técnicos para llevar a cabo una tarea los mismos que no están patentados, la fidelidad de los clientes son parte del activo de la empresa que es exitosa y cuantificada en los mercados financieros que determinan gran parte de la organización (Funes-Cataño \& Hernández-Garnica, 2001). 
Otro de los precursores en este campo (Calderón, 2008), refiere que el capital intelectual es la suma de todos los conocimientos adquiridos en la organización y que poseen los empleados y que permiten tomar decisiones correctas, que otorgan a la empresa ventaja competitiva, el capital intelectual es simplemente el plus de conocimientos en la organización y que permite la ventaja competitiva.

Así, la definición del capital intelectual, cambia como comúnmente se le ha venido tratando es decir el conocimiento es el entendimiento de un individuo y como mediantes sus conocimientos y habilidades ayuda a mejorar la calidad de la empresa, como distribuye su tiempo para hacer frente a diferentes problemas que día a día se tiene en un puesto de trabajo, el manejo de sistemas informáticos, la capacidad de innovar, aprender para lograr desenvolverse adecuadamente tomar acciones adecuadas frente a conflictos presentados en las organizaciones, de este modo el conocimiento y preparación de los miembros de la organización, ayudada por sistemas tecnológicos, sumada a un manejo organizativo adecuado conllevan a generar valor agregado.

El capital intelectual y las estructuras organizativas de acuerdo con (Calderón, 2008) menciona que puede servir para lograr ser más competitivos frente a diferentes competidores a corto como a largo plazo, pero en varios casos estas oportunidades de obtener recursos son muy difíciles de encontrar dejando así pasar cosas grandes. (Calderón, 2008) refiere que el capital intelectual no es solamente la capacidad de pensar de una persona, también las inversiones que hayan realizado las organizaciones en sus marcas y productos y que no se pueden valorizar de una manera monetaria, siendo así activos los conocimientos, pero con valor cero.

De esta manera los conocimientos de un empleado son recursos intangibles que son medidos por su experiencia y capacidades, (Edvinsson \& Malone, 1997) no tienen una definición de lo que significa el capital intelectual, pero estos autores si lo clasifican en capital humano conocimientos de sus empleados y la capacidad que tiene sus mandos jerárquicos para dirigir y controlar una organización, también señalan que los clientes son el corazón de toda organización ya que al estar satisfechos por un bien o servicio 
Diego Armando Coello-Paute; Juan Carlos Erazo-Álvarez; Cecilia Ivonne Narváez-Zurita; Juan Edmundo Álvarez-Gavilanes

fidelizaran una empresa. El capital estructural, la infraestructura y la inversión que han hecho los gerentes a la organización, equipos magnéticos, softwares, hardware, sistemas operativos y algo que es de mucha importancia patentar los productos y servicios realizados por la empresa (Sánchez-Medina et al., 2007).

En la era moderna el capital intelectual evoluciono y ha experimentado una serie de cambios y transformaciones, el concepto de capital humano perdió interés debido a la importancia que tiene el trabajador para las empresas como también para las organizaciones siendo un elemento esencial el cual cuenta con herramientas y conocimientos adquiridos a lo largo del tiempo, y que permitirán ayudar a generar más y mejor productividad en el desarrollo diario de las diferentes actividades de la empresa que mejorarara los indicadores financieros de una organización. En esta era moderna con la introducción de equipos magnéticos han ayudado para que los empleados desarrollen de mejor manera habilidades ayudados de un nivel tecnológico adecuado y así lograr desarrollar diferentes tareas en menos tiempo posible y al menor costo.

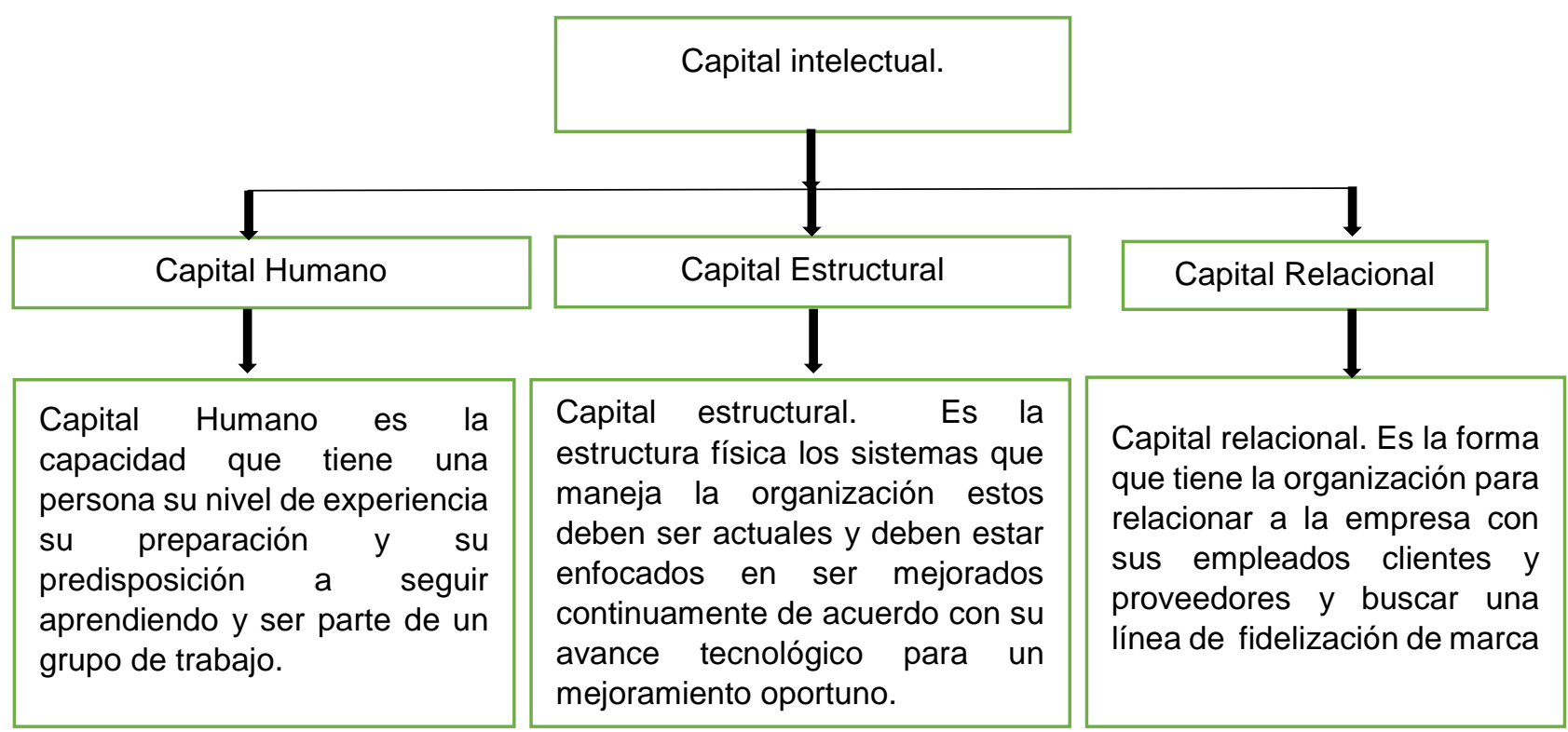

Figura 1. Tipos de capital intelectual.

Fuente: Chiavenato (2009). 
Diego Armando Coello-Paute; Juan Carlos Erazo-Álvarez; Cecilia Ivonne Narváez-Zurita; Juan Edmundo Álvarez-Gavilanes

Capital humano: son los conocimientos de los individuos, destrezas y experiencias obtenidas frente a sus competidores y que le han permitido desarrollarse de manera adecuada en un lugar de trabajo, los conocimientos obtenidos su capacidad de hacer frente a diferentes problemas que se dan a diario en una organización pero que deben ser resueltos de manera oportuna y correcta, ayudando así a seguir procesos establecidos por las diferentes áreas de trabajo, una destreza adecuada y acompañada de experiencia permiten mezclar el conocimiento con la tecnología y mejorar de forma permanente.

Capital estructural: el capital estructural es básicamente la estructura que se usa y se incorpora para capacitar al capital humano que está dividido en inversión, sistemas herramientas, operaciones logísticas y plataformas magnéticas, tampoco tener personas también contar con colaboradores que puedan utilizar el capital estructural de la empresa y usarlos adecuadamente a sus labores diarias en la actualidad las empresas han hecho muchas inversiones en tener infraestructura necesaria y canales magnéticos para mejorar la imagen frente a los competidores, pero esto debe ser adaptado adecuadamente a los empleados para que puedan manejar las herramientas para generar valor agregado

Capital relacional: este tipo de capital hace referencia a los clientes que tiene la organización y a los futuros clientes que quiere atraer y a los que va dirigido cierto producto o servicio, es la forma como ven los clientes al momento de hacer algún tipo de negocio o convenio y la seriedad que muestra frente a sus competidores, otro factor importante es cómo ven los clientes sus indicadores financieros su tiempo de permanencia en el mercado la manera como se ha venido desarrollando frente a las amenazas por el impacto económico y su capacidad para hacer frente diversas debilidades volviéndoles así fortalezas, por lo tanto este capital es la forma como la empresa se relaciona con sus competidores proveedores clientes y su entorno en general (Chiavenato, 2009). 
Diego Armando Coello-Paute; Juan Carlos Erazo-Álvarez; Cecilia Ivonne Narváez-Zurita; Juan Edmundo Álvarez-Gavilanes

Si el empleado tiene un entrenamiento adecuado, demostrara las habilidades que se necesitan para desempeñar una actividad solicitada, debe contar con destrezas necesarias para hacer frente a diversas situaciones que se dan a lo largo de una jornada laboral y de esa manera tomar decisiones adecuadas en tareas de complejidad que necesitan respuestas rápidas pero eficientes, lo mejor es estar preparando al personal para que pueda mejorar día a día y direccionar al éxito a una empresa, es ahí la importancia de contar con perfiles adecuados y de acuerdo con su experiencia para tener mayor rendimiento con un crecimiento rápido y definir debilidades, es así como la administración por competencias busca tener perfiles adecuados para satisfacer de mejor manera las necesidades de la organización (Chiavenato, 2007), así mismo, (Chiavenato, 2009), define los seis componentes básicos del departamento de recursos humanos:

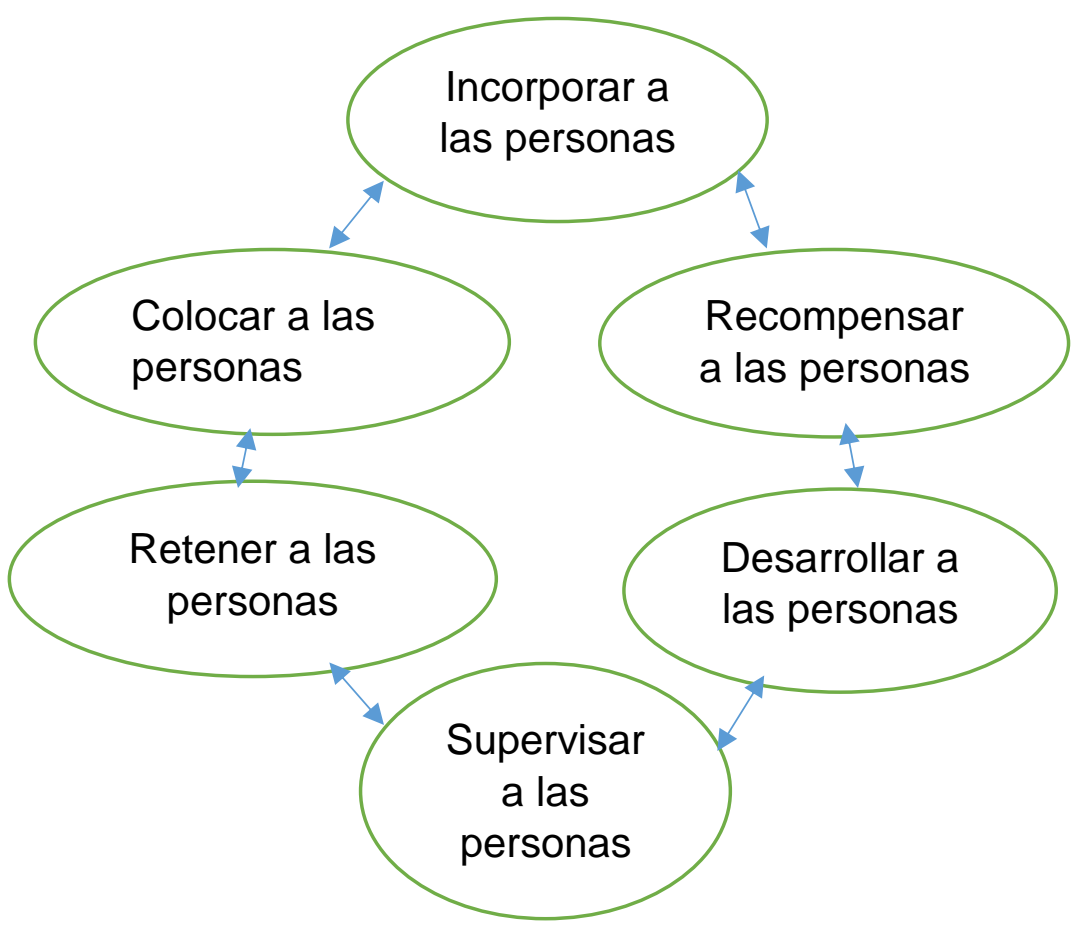

Figura 2. Componentes básicos de la administración por competencias. Fuente: Chiavenato (2009). 
Diego Armando Coello-Paute; Juan Carlos Erazo-Álvarez; Cecilia Ivonne Narváez-Zurita; Juan Edmundo Álvarez-Gavilanes

1. Métodos para incorporar personal: son los procesos que ejecutan las organizaciones para incluir nuevo personal para abastecer necesidades internas incluye la incorporación y clasificación adecuada.

2. Métodos para direccionar al personal: Son diferentes tareas y procesos que se diseñan en la organización para orientar el cumplimiento de objetivos y que serán evaluados en su periodo. Para definir las distintas tareas que se deben ejecutar en la organización para guiar y evaluar el desempeño laboral de los empleados.

3. Estrategias para motivar a los empleados: Son instrumentos que permiten incentivar a los empleados que incluyen los planes remunerativos afiliaciones seguros privados que ayudan a tener empleados leales y comprometidos con la organización.

4. Estrategias para innovar a los empleados: Son planificaciones que las organizaciones hacen a corto y largo plazo para entrenar y retro-alimentar a su personal para un mejor desarrollo productivo que implica mejorar las capacidades de aprendizaje como las competencias y adecuaciones a cambios en la organización.

5. incentivos para mantener a los empleados: Son metodologías estratégicas que utilizan las empresas para retener a sus mejores funcionarios manteniendo un ambiente laboral bueno y una cultura organizacional adecuada planes remunerativos óptimos y una infraestructura moderna como también manuales de funciones actualizados

6. Sistemas para auditar a los empleados. Son exámenes que permiten conocer y controlar las actividades de los empleados, ayudados de auditorías, para tener un control amplio del desempeño y sus funciones realizadas. (Chiavenato, 2011). 
Diego Armando Coello-Paute; Juan Carlos Erazo-Álvarez; Cecilia Ivonne Narváez-Zurita; Juan Edmundo Álvarez-Gavilanes

El capital intelectual es una herramienta de gestión que permite a los gerentes lograr combinar sus activos intangibles con sus activos tangibles conocidos y la capacidad de sus empleados de desarrollarse junto a estos, como pueden adaptarse al cambio motivados de entrenamientos adecuados y la inteligencia que les permitirá aprender de una forma rápida y acertada, incluyendo no solo al personal interno, también a los proveedores clientes cambios de nombres en sus marcas e imagen institucional, es así que el capital intelectual debe siempre contar con capacitaciones continúas que pueda brindar la institución y que ayudados de una inversión adecuada conlleven a crear valor agregado en el tiempo (Sánchez-Medina, et al., 2007).

\section{La gestión del capital intelectual y su incidencia en la cultura organizacional.}

La cultura organizacional es de total importancia porque permite identificar las normas que direccionan a la institución como también a los empleados al cumplimiento de los objetivos, ya que esto afecta de manera directa a sus funciones administrativas como operativas, los gerentes de área desempeñan un papel importante en la consecución de una cultura óptima por medio de sus decisiones las mismas que deben llevar a tomar acciones adecuadas en respuesta a problemas que afectan el giro del negocio en cualquier nivel de operación, las decisiones que tomen sus gerentes deben ser óptimas y las más acertadas posibles de esta manera se busca crear una cultura organizacional y eficaz que permita llegar a los objetivos institucionales deseados (Chiavenato, 2009). El capital intelectual y la gestión de capital humano en las empresas es el eje fundamental para un desempeño adecuado, la misma que se apoya en diferentes procesos y normas de las organizaciones, estas ayudan a implementar herramientas de control, para buscar, innovar, incentivar y mantener a sus empleados, el conocimiento en la actualidad es esencial y el mayor desafío está en conseguir ser el mejor, el éxito de sus gerentes está en conseguir que el conocimiento sea eficiente y beneficioso, para esto los administradores vieron en la gestión del capital intelectual como una herramienta de dirección basada en estrategias orientadas a conseguir sus objetivos tanto en corto como 


\section{Diego Armando Coello-Paute; Juan Carlos Erazo-Álvarez; Cecilia Ivonne Narváez-Zurita; Juan Edmundo Álvarez-Gavilanes}

largo plazo, ayudada de una capacitación y formación fuerte de su personal. (RamónOchoa, et al., 2019).

El capital humano está en la mente de las personas y se encuentra guiada por una cultura organizacional y adecuada, por lo tanto el éxito de una organización está direccionada por el capital intelectual de sus integrantes, este tipo de capital es la riqueza del mundo actual y a la vez la fortaleza de las organizaciones en un futuro, en la actualidad los bienes más valiosos de las organizaciones con éxito son sus empleados, es así que las grandes organizaciones han visto necesario capacitar a quienes ya están capacitados, por cuanto estos son la línea directa con los clientes proveedores y otros, debido a que un empleado capacitado tomara decisiones adecuadas frente a problemas que no necesitan apoyo para ser resuelta, llevando a cabo varias tareas de manera fácil y oportuna (Erazo-Álvarez \& Narváez-Zurita, 2020).

Un gran porcentaje del capital intelectual se encuentra constituido por el capital humano que son las habilidades y capacidades. El capital humano es definido por los funcionarios que son parte fundamental de las instituciones, la gestión del capital humano, representada por empleados bien entrenados que deben ser retenidos e innovados, más aún, si sus aportes y sus conocimientos ayudan a mejorar día a día el giro del negocio Un capital invisible compuesto de activos intangibles medidos por los conocimientos de sus miembros, el valor de una organización en el mercado no solo se valoriza por el nivel patrimonial físico al momento de una negociación también del valor de sus empleados y el aporte que estos hacen, en la actualidad el conocimiento se ha convertido en una herramienta institucional más fuerte y que representa una fortaleza que es mejor que el mismo valor monetario (Chiavenato, 2007).

Dentro de la gestión de la cultura organizacional se ubican una serie de procesos para un buen manejo de selección, se detallan a continuación. 
Diego Armando Coello-Paute; Juan Carlos Erazo-Álvarez; Cecilia Ivonne Narváez-Zurita; Juan Edmundo Álvarez-Gavilanes

\section{Investigación y descripción de cargos.}

1. Pruebas de conocimiento

2. Afiliaciones y firmas de contratos

3. capacitación e incorporación

4. Identificación de funciones

5. Plan de remuneraciones

6. Medición de resultados

7. Reuniones informativas

8. Plan de capacitaciones

9. Conoce a tu empleado

10. Cultura organizacional (Chiavenato, 2009).

11.

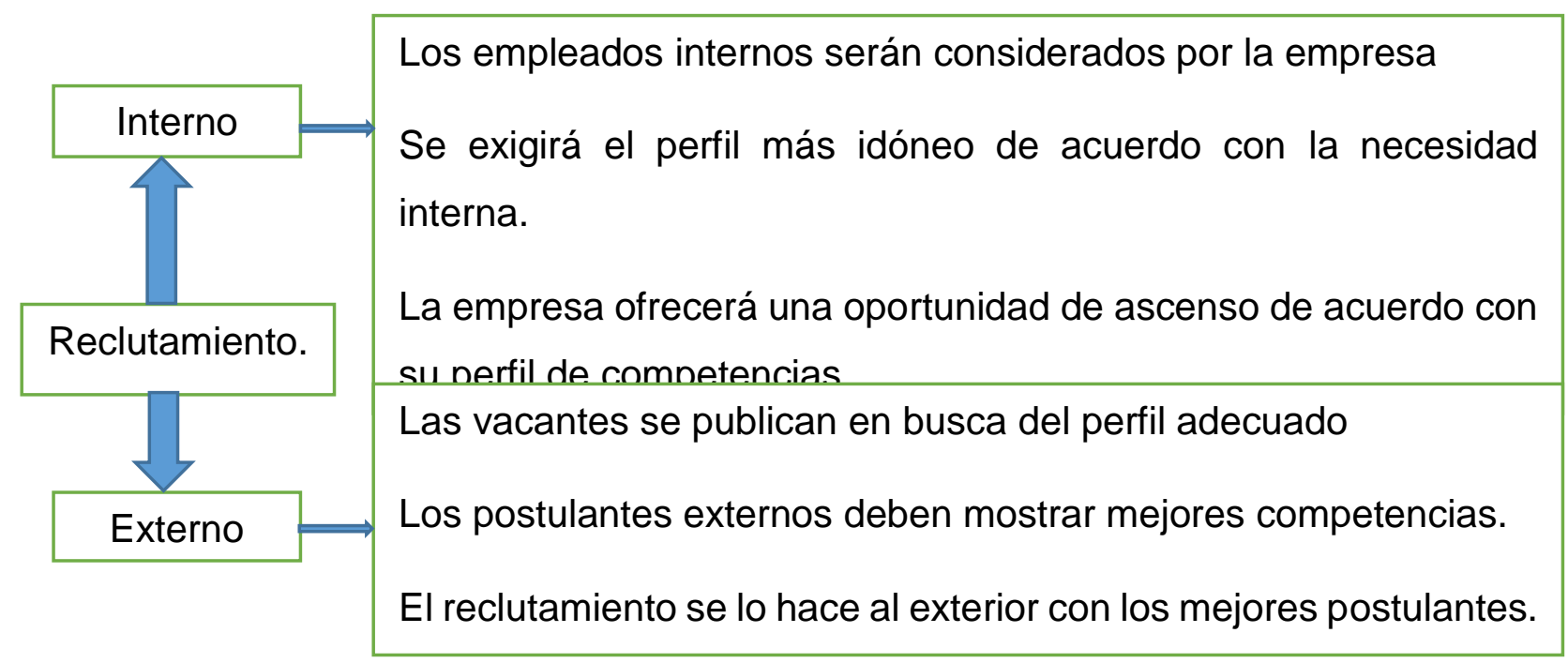

Figura 3. Competencias necesarias para un reclutamiento exitoso.

Fuente: Chiavenato (2009). 


\section{Diego Armando Coello-Paute; Juan Carlos Erazo-Álvarez; Cecilia Ivonne Narváez-Zurita; Juan Edmundo Álvarez-Gavilanes}

Como todos saben, las empresas empiezan con la visión de tener crecimiento económico y ser sustentable en el tiempo, bajo este pensamiento, el capital intelectual desempeña un rol esencial en el cumplimiento de objetivos institucionales, por cuanto mediante la capacidad de los empleados se desarrollan las planificaciones y una serie de procesos, la responsabilidad que cada uno de los funcionarios de los diferentes departamentos será clave para el crecimiento global de la organización y lograr tener indicadores fuertes y sólidos ya que todas las áreas estarán bien direccionadas obteniendo tiempos de operación correctos y sin errores que conlleven a pérdidas operacionales (Díaz, 2007).

La búsqueda de las empresas por tener personal capacitado eh idóneo es primordial, ya que es el principal objetivo para lograr la eficiencia anhelada por el empleador, y en los cuales hacen planes a corto plazo buscando mejorar sus ingresos, pero siempre buscando ejecutar las mejores contrataciones para llenar las vacantes en diferentes áreas de interés y que necesitan apoyo de un empleado con competencias diferentes a las existentes, una contratación adecuada permitirá a la institución tener a los mejores empleados y estos a su vez ayudarán a conseguir los objetivos deseados en el menor tiempo posible, logrando generar valor agregado a la empresa cumpliendo con las expectativas esperadas, tomando en cuenta que la visión y misión de una organización, está siempre está ligada a ser sostenible en el tiempo. (Ramón-Ochoa, et al., 2019).

\section{Dirección del capital humano en las instituciones y su efecto en la calidad del servicio}

La dirección y gestión del talento humano como lo describen muchos autores, es un área del aprendizaje continuo aplicada en la actualidad por los empleadores, en la cual el funcionario de la organización se considera como el capital humano y un factor más importante que es parte integral del desempeño diario de la empresa, y su administración y conocimientos debe ser administrada y direccionada en consecución de objetivos primarios y secundarios, para esto es primordial hacer un estudio interno como las competencias laborales ayudadas del conocimiento y las habilidades de sus integrantes 


\section{Diego Armando Coello-Paute; Juan Carlos Erazo-Álvarez; Cecilia Ivonne Narváez-Zurita; Juan Edmundo Álvarez-Gavilanes}

hacen que las metas propuestas en el plan integral de objetivos se estén cumpliendo en un menor costó posible y con la mayor eficiencia esperada (Chiavenato, 2007).

La calidad del servicio son los esfuerzos que cada organización hace en la búsqueda de una cultura organizacional y orientada en satisfacer a sus clientes y proveedores, la cual permita crear bienes y brindar servicios adecuados y de la mejor calidad, para mejorar su productividad e incrementar sus ingresos, garantizando a su vez, la sostenibilidad en el tiempo y siendo mejor ante la competencia de la organización en los mercados donde opera la misma, y por ende la satisfacción de sus clientes, cuya satisfacción sólo se logra cuando los clientes cubren sus percepciones y expectativas del servicio solicitado o de los bienes solicitados. Por lo tanto, cada vez es más fuerte la inclinación por lograr convertir al servicio en la herramienta clave de los negocios y en una estrategia frente a la competencia (Atencio-Cárdenas, et al., 2007).

Sin embargo, calidad del servicio son los diferentes protocolos que implementan las empresas a través de sus empleados, buscando siempre satisfacer los deseos y necesidades de sus usuarios, no obstante la calidad está relacionada en mantener a sus clientes satisfechos y de esta manera las organizaciones buscan vender sus bienes y servicios mediante una venta cruzada, brindando un servicio de calidad y haciendo publicidad mediante su propios clientes, logrando obtener clientes fieles, es decir mantener a los clientes actuales y lograr captar nuevos clientes de los mercados mediante canales de márketing relacional que se han convertido en la estrategia actual de los empresarios que han entendido que un buen servicio y de calidad crea una ventaja competitiva y fuerte frente a sus competidores (Duque-Oliva, 2005). 
Revista Arbitrada Interdisciplinaria KOINONIA

Año 2020. Vol V. №3. Especial: Administración

Hecho el depósito de Ley: FA2016000010

ISSN: 2542-3088

FUNDACIÓN KOINONIA (F.K). Santa Ana de Coro. Venezuela.

Diego Armando Coello-Paute; Juan Carlos Erazo-Álvarez; Cecilia Ivonne Narváez-Zurita; Juan Edmundo Álvarez-Gavilanes

\section{METODOLOGÍA}

La presente investigación fue de alcance descriptivo de carácter transversal, puesto que la recolección de los datos informativos se hizo en un solo periodo y se expuso sus relaciones e impactos, se usaron encuestas in-situ con el afán de recolectar datos informativos que permitan examinar las variables, por esta razón, la herramienta manejada fue el cuestionario ordenado organizado. El universo poblacional estuvo conformado por un total de 143 colaboradores administrativos, servicio directo con el cliente, de la cooperativa de ahorro y crédito Erco Ltda, se aplicó la encuesta utilizando y cuestionario en escala tipo Likert, mediante formulario de Google (https://docs.google.com/forms), aplicándose estadística descriptiva para el procesamiento de la información.

\section{RESULTADOS}

Se presentan los resultados de la investigación:

\section{Tabla 1.}

Planificación estratégica.

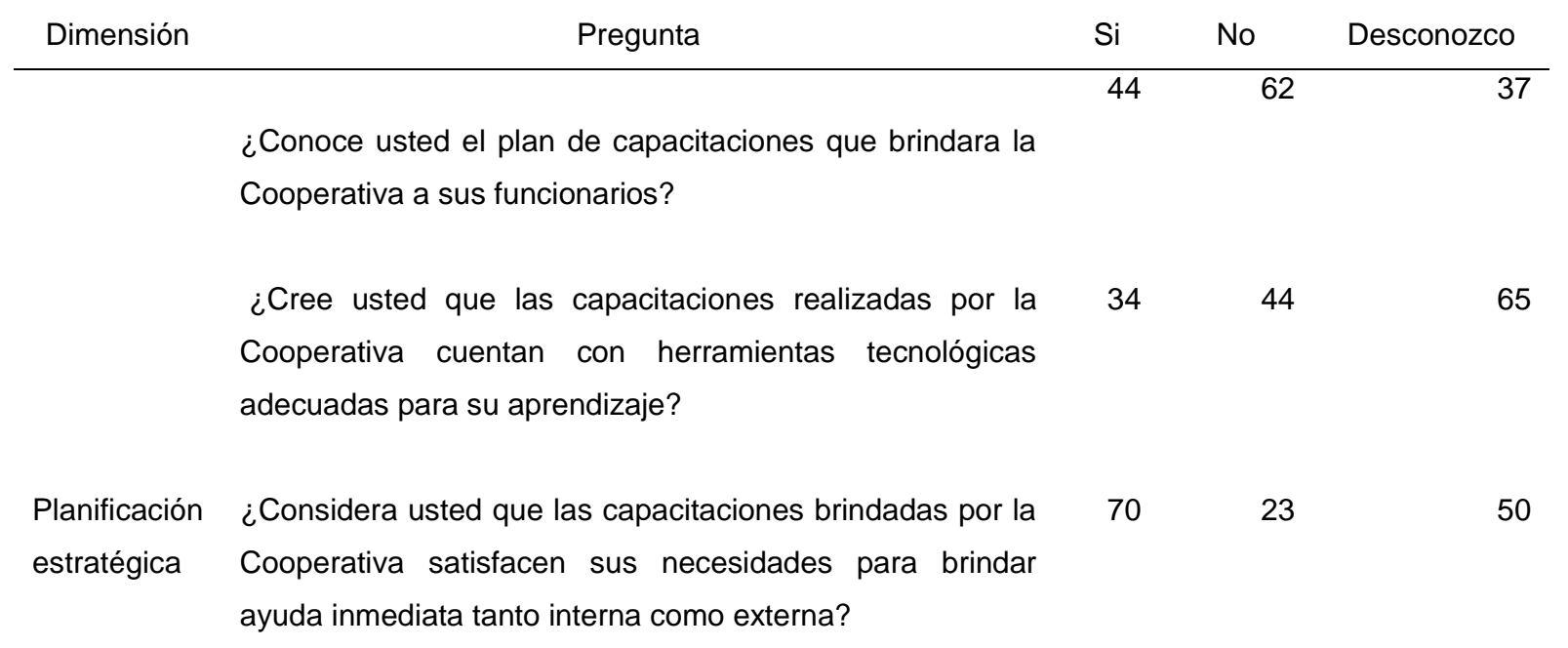


Revista Arbitrada Interdisciplinaria KOINONIA

Año 2020. Vol V. №3. Especial: Administración

Hecho el depósito de Ley: FA2016000010

ISSN: 2542-3088

FUNDACIÓN KOINONIA (F.K). Santa Ana de Coro. Venezuela.

Diego Armando Coello-Paute; Juan Carlos Erazo-Álvarez; Cecilia Ivonne Narváez-Zurita; Juan Edmundo Álvarez-Gavilanes

¿Está usted de acuerdo en recibir capacitaciones de forma

117

26

virtual cuando se pretenda lanzar un producto nuevo a

funcionamiento?

¿Considera usted que el nivel profesional está acorde al 100

28

perfil requerido para determinado cargo?

¿Cree usted que la capacitación brindada por la

83

60

Cooperativa "cuando ingreso a laborar" fue la adecuada

para ejercer su puesto de trabajo?

Planificación estratégica

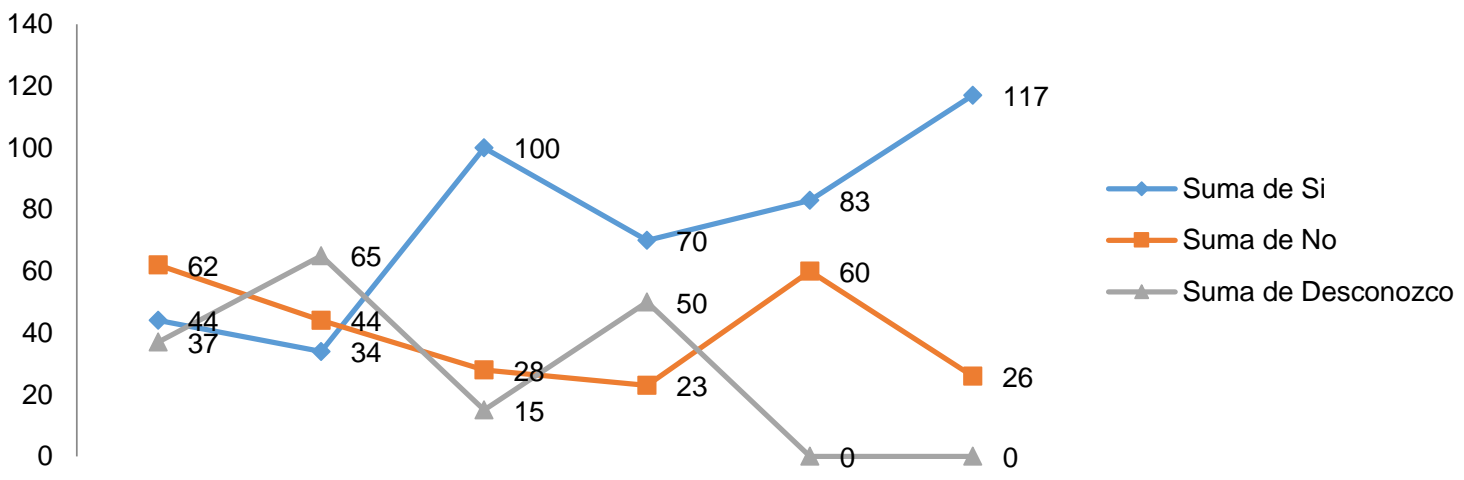

Figura 1. Resultados de la encuesta aplicada a la planificación estratégica 
Revista Arbitrada Interdisciplinaria KOINONIA

Año 2020. Vol V. №3. Especial: Administración

Hecho el depósito de Ley: FA2016000010

ISSN: 2542-3088

FUNDACIÓN KOINONIA (F.K). Santa Ana de Coro. Venezuela.

Diego Armando Coello-Paute; Juan Carlos Erazo-Álvarez; Cecilia Ivonne Narváez-Zurita; Juan Edmundo Álvarez-Gavilanes

Tabla 2.

Cuantificación.

\begin{tabular}{|c|c|c|c|c|c|}
\hline Dimensión & Pregunta & Excelente & Muy bueno & Bueno & Regular \\
\hline \multirow[t]{5}{*}{ Cuantificación } & $\begin{array}{l}\text { ¿Cómo usted calificaría las capacitaciones } \\
\text { recibidas por la institución? }\end{array}$ & 16 & 55 & 59 & 13 \\
\hline & $\begin{array}{l}\text { ¿Cómo califica usted las capacitaciones } \\
\text { impartidas por los funcionarios de la } \\
\text { Cooperativa? }\end{array}$ & 16 & 51 & 64 & 12 \\
\hline & $\begin{array}{l}\text { ¿Considera usted que las herramientas } \\
\text { tecnológicas implementadas por la } \\
\text { Cooperativa están al mismo nivel tecnológico } \\
\text { que las demás financieras? }\end{array}$ & 21 & 25 & 41 & 56 \\
\hline & $\begin{array}{l}\text { ¿Cree usted que el mando jerárquico superior } \\
\text { ha logrado capacitar eficientemente a sus } \\
\text { funcionarios? }\end{array}$ & 30 & 33 & 45 & 35 \\
\hline & $\begin{array}{l}\text { ¿Considera usted que la auto preparación le } \\
\text { permitirá desarrollarse de mejor manera en la } \\
\text { Cooperativa y aspirar a mejores cargos? }\end{array}$ & 23 & 45 & 67 & 8 \\
\hline
\end{tabular}

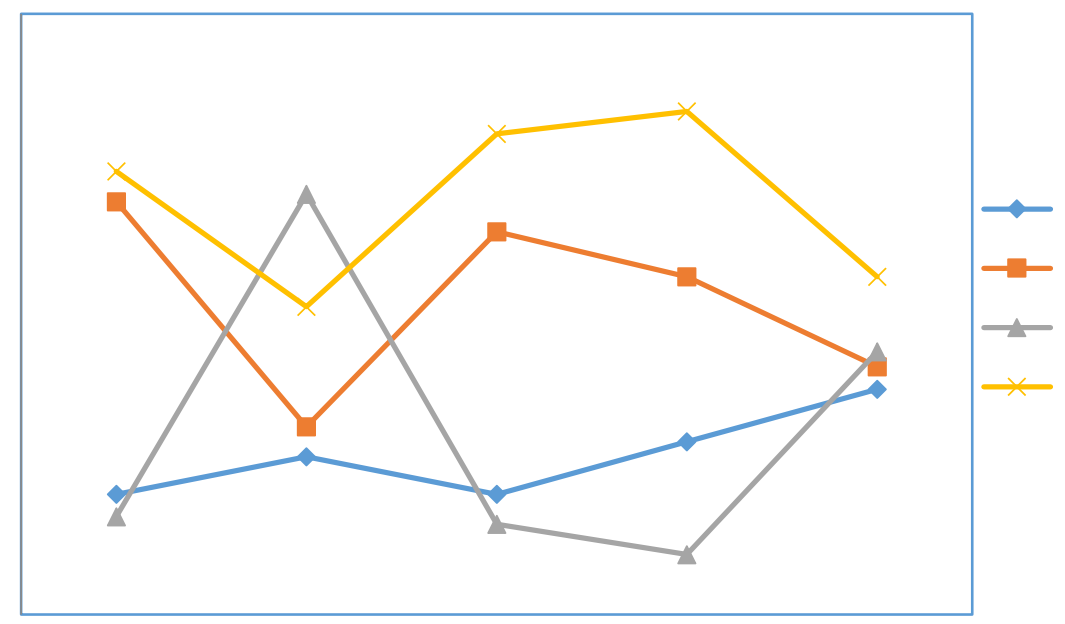

Figura 2. Resultados de la encuesta aplicada a la cuantificación. 
Revista Arbitrada Interdisciplinaria KOINONIA

Año 2020. Vol V. №3. Especial: Administración

Hecho el depósito de Ley: FA2016000010

ISSN: 2542-3088

FUNDACIÓN KOINONIA (F.K). Santa Ana de Coro. Venezuela.

Diego Armando Coello-Paute; Juan Carlos Erazo-Álvarez; Cecilia Ivonne Narváez-Zurita; Juan Edmundo Álvarez-Gavilanes

\section{Tabla 3.}

Estandarización.

\begin{tabular}{|c|c|c|c|c|c|}
\hline Dimensión & Pregunta & Mucho & Bastante & Algo & $\begin{array}{l}\text { Muy } \\
\text { poco }\end{array}$ \\
\hline \multirow[t]{5}{*}{ Estandarización } & $\begin{array}{l}\text { ¿Considera usted que los funcionarios de la } \\
\text { cooperativa están capacitados para } \\
\text { desempeñar los diferentes cargos? }\end{array}$ & 15 & 10 & 79 & 39 \\
\hline & $\begin{array}{l}\text { ¿Cuándo usted fue capacitado, considera que } \\
\text { el facilitador, ofreció el profesionalismo, } \\
\text { capacidades y destrezas necesarias para } \\
\text { brindar una enseñanza eficaz? }\end{array}$ & 15 & 44 & 78 & 6 \\
\hline & $\begin{array}{l}\text { ¿Las capacitaciones hechas por la } \\
\text { Cooperativa le han ayudado a resolver } \\
\text { problemas suscitados en su puesto de } \\
\text { trabajo? }\end{array}$ & 20 & 35 & 40 & 48 \\
\hline & $\begin{array}{l}\text { ¿Considera usted que las personas que están } \\
\text { en el área de apoyo están bien capacitadas } \\
\text { para poder brindar ayuda oportuna? }\end{array}$ & 23 & 37 & 45 & 38 \\
\hline & $\begin{array}{l}\text { ¿Considera usted que las capacitaciones } \\
\text { brindadas por la Cooperativa son claras y } \\
\text { ayudan a mejorar su trabajo? }\end{array}$ & 18 & 33 & 82 & 10 \\
\hline
\end{tabular}

\section{Estandarización}

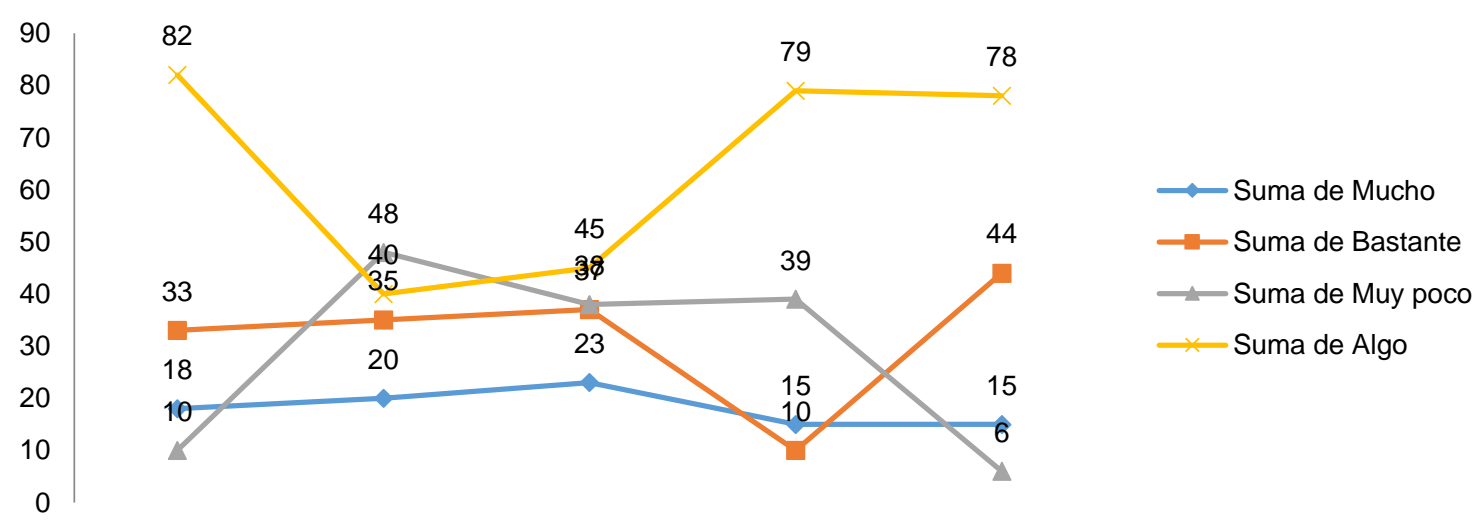

Figura 3. Resultados de la encuesta aplicada a la estandarización. 


\section{Diego Armando Coello-Paute; Juan Carlos Erazo-Álvarez; Cecilia Ivonne Narváez-Zurita; Juan Edmundo Álvarez-Gavilanes}

Luego de haber realizado el estudio de cada una de las preguntas y sus respuestas se, ha podido identificar según las dimensiones propuestas que no hay semejanza en las respuestas de los diferentes funcionarios de la institución debido a que no existe una planificación estratégica de los diferentes departamentos sobre una programación anual de capacitaciones y se puede identificar ya que un $43,3 \%$ no conoce sobre el tema y un $25,8 \%$ desconoce si habrá inducciones, teniendo solo un 30,7\% conocimiento de las capacitaciones que se pretendan brindar por parte de la cooperativa.

Con respecto al tema de la encuesta realizada a la dimensión cuantificación un 41.2\% de los funcionarios de la institución consideran que las capacitaciones recibidas en diferentes temas no han sido de su entera satisfacción demostrando así que las inducciones realizadas por funcionarios que han facilitado las capacitaciones no han sido en su gran parte útiles y no son vinculadas de manera eficiente a los diferentes funcionarios que buscaban esclarecer ciertas dudas por esta razón se ha determinado que un $53.15 \%$ muestra descontento de los funcionarios que han preparado un tema para ser impartido.

Otro tema que de preocupación que se puede observar por las encuestas realizadas es que muchas de las capacitaciones no han sido claras y que no han contado con herramientas tecnológicas adecuadas para su entendimiento dificultando tener una comprensión exitosa de sus participantes.

Con los datos obtenidos se pudo concluir que la institución no cuenta con un plan de capacitaciones adecuado y que las capacitaciones que se han venido dando no satisfacen de manera eficiente a sus empleados por tal motivo esto puede llevar a entorpecer muchos procesos operativos y atraer pérdidas de tiempo como recursos por tal motivo se recomienda desarrollar un plan de capacitaciones con un recurso destinado para este rubro y que las capacitaciones que se planifiquen sean revisadas para ser de impacto para los colaboradores y de ser posible que cuenten con herramientas tecnológicas que ayuden su mejor comprensión como también el facilitador cuente con las destrezas necesarias para poder llegar de mejor manera a su oyente. 


\section{PROPUESTA}

\section{Esquema de la propuesta del capital intelectual}

\section{CAPITAL INTELECTUAL}

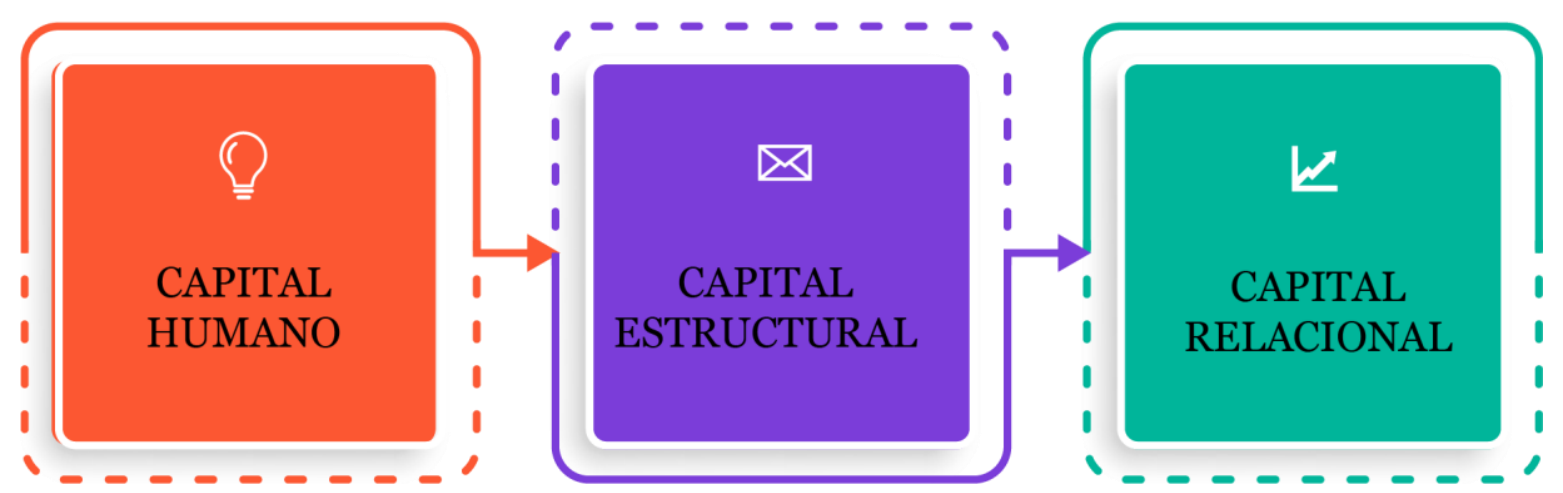

Figura 4. Propuesta del capital intelectual.

El sector financiero cooperativo es una organización de constante cambio el mismo que nos permite realizar una amplia investigación en cuanto al capital intelectual se refiere debido a los grandes cambios que tiene que enfrentar para ser más riguroso fuerte y competitivo en pro de buscar un desarrollo constante como sostenible en el tiempo En el presente estudio mediremos el capital intelectual de la Cooperativa de ahorro y crédito Erco Ltda cuya actividad principal es la intermediación financiera mediante la venta de productos y servicios financieros el mismo que ha mostrado un crecimiento fuerte a pesar de la competencia que tiene en el país, la clave del éxito de esta financiera está en el adecuado manejo de sus activos intangibles, conocimientos aplicados en la actividad diaria, la predisposición de sus miembros de interactuar de manera eficiente con sus socios, clientes y su entorno en general.

Es así que el capital humano de la cooperativa de ahorro y crédito Erco Ltda es el valor más importante con el que cuenta la cooperativa, medida por las destrezas, conocimientos y habilidades de sus integrantes considerados como un activo intangible 


\section{Diego Armando Coello-Paute; Juan Carlos Erazo-Álvarez; Cecilia Ivonne Narváez-Zurita;} Juan Edmundo Álvarez-Gavilanes

que no se puede medir debido a que contablemente tiene valor de cero, que no se muestra en la contabilidad interna, pero que se puede medir por el logro de los objetivos institucionales. La cooperativa de ahorro y crédito Erco Ltda ha realizado avances significativos en su capital humano como por ejemplo buscar capacitar a aquellos empleados que tienen contacto directo con los socios y clientes, pero muchas de estas capacitaciones no han sido las más efectivas y muestran debilidades, las mismas que se han podido evidenciar en la información recolectada por tal motivo se recomienda hacer un seguimiento y evaluación tanto del capacitado como del capacitador y llevar un registro para no caer otra vez en esta problemática.

En tanto a lo referente al capital estructural la cooperativa de ahorro y crédito Erco Ltda ha realizado avances significativos tanto en tecnología como en desarrollo y almacenamiento de base de datos debido a su crecimiento bien manejado cuenta con marcas, patentes, tecnología, manejo de archivos, almacenamiento de información, propiedad planta y equipo, dichos conocimientos son propios de la institución y no se encuentran en la mente de su personal y permite una ventaja de capital propio que a su vez sí cuenta esta institución financiera. Según este estudio se puede evidenciar que la cooperativa Erco Ltda. cuenta con una estructura sólida de igual manera con reglamentos y manuales de funciones adecuados los cuales se han ido adecuando a lo largo del tiempo, así mismo cuenta con herramientas tecnológicas y espacios modernos para sus colaboradores, socios y todos aquellos que interactúen con la institución, sin embargo se propone que el departamento de recursos humanos coordine con los diferentes departamentos la utilización de los sistemas implementados en varias agencias que dan servicios al socio y departamentos que brindan soporte y que estos sistemas ya implementados sean usados correctamente, en el caso de no contar con una herramienta tecnológica sugerir la implementación de acuerdo a las necesidades previstas en el puesto de trabajo.

Por otra ala del negocio con respecto al capital relacional se puede evidenciar que la cooperativa ha logrado una distribución adecuada de su cartera de crédito y que este es 


\section{Diego Armando Coello-Paute; Juan Carlos Erazo-Álvarez; Cecilia Ivonne Narváez-Zurita;} Juan Edmundo Álvarez-Gavilanes

uno de los aportes más importantes de esta financiera debido a su giro del negocio, como también se puede notar el crecimiento que ha tenido en número de socios he integración con la comunidad en sus mercados financieros, por otra parte mediante este tipo de capital podemos medir el desempeño del capital intelectual como también la forma para relacionar a la organización con sus empleados, socios, proveedores, competencia, directivos y entorno en general, incluye publicidad adecuada, que permite que sus socios y los futuros socios vean en esta institución financiera una oportunidad de invertir y asociarse.

Como se puede evidenciar la cooperativa Erco Ltda. ha logrado relacionarse de manera exitosa en diferentes zonas del país como también con sus colaboradores mediante una adecuada cultura organizacional con un claro manual de funciones y procedimientos logrando así un crecimiento sostenible con una cartera solida e indicadores financieros fuertes, sin embargo muchas personas del medio no saben de los servicios que brinda la institución, por tal motivo se propone realizar un mejoramiento de la publicidad y ofrecer servicios en línea que sean fáciles de usar y que incrementen el desarrollo de las oficinas mediante una relación fuerte entre sus colaboradores, socios y clientes, también podemos proponer que la cooperativa cree planes de capacitación que relacionen directivos-colaboradores con una planeación adecuada de acuerdo a la necesidad de la institución con un levantamiento adecuado de información mediante su departamento de educación cooperativa creando así confianza para lograr fidelización de sus socios y clientes. 
Revista Arbitrada Interdisciplinaria KOINONIA

Año 2020. Vol V. №3. Especial: Administración

Hecho el depósito de Ley: FA2016000010

ISSN: 2542-3088

FUNDACIÓN KOINONIA (F.K). Santa Ana de Coro. Venezuela.

Diego Armando Coello-Paute; Juan Carlos Erazo-Álvarez; Cecilia Ivonne Narváez-Zurita; Juan Edmundo Álvarez-Gavilanes

\section{Tabla 4.}

Cálculo del valor intelectual y sus componentes realizados en la organización.

\begin{tabular}{|c|c|c|c|c|c|}
\hline & 2015 & 2016 & 2017 & 2018 & 2019 \\
\hline \multicolumn{6}{|l|}{ Capital humano } \\
\hline inversión en capacitación & 5405,37 & 16568,64 & 15135,61 & 12332,42 & 12500,85 \\
\hline \multicolumn{6}{|l|}{ Capital estructural } \\
\hline Activos & 1267740,94 & 1468105,7 & 1607658,1 & 2201722,1 & 3313918,2 \\
\hline $\begin{array}{l}\text { Total de Capital humano y } \\
\text { estructural }\end{array}$ & 1273146,31 & 1484674,4 & 1622793,7 & 2214054,5 & 3326419 \\
\hline Inversión individual & 54,60 & 159,31 & 135,14 & 91,35 & 70,63 \\
\hline \multicolumn{6}{|l|}{ Capital relacional } \\
\hline Total de empleados & 99 & 104 & 112 & 135 & 177 \\
\hline Total de socios & 26808 & 30530 & 35004 & 50082 & 60113 \\
\hline Total de créditos & 8334 & 9444 & 11278 & 14650 & 19068 \\
\hline Total de capital relacional & 35241 & 40078 & 46394 & 64867 & 79358 \\
\hline \multicolumn{6}{|l|}{ Capital humano } \\
\hline \multicolumn{6}{|l|}{ Colaboradores con título } \\
\hline profesional & 44 & 51 & 64 & 81 & 120 \\
\hline Rotación de colaboradores & 34 & 26 & 29 & 33 & 45 \\
\hline \multicolumn{6}{|l|}{ Colaboradores con formación } \\
\hline permanente & 99 & 104 & 112 & 135 & 177 \\
\hline Colaboradores formados & 99 & 104 & 112 & 135 & 177 \\
\hline Antigüedad / 30 años de servicio & 3,3 & 3,5 & 3,7 & 4,5 & 5,9 \\
\hline Total capital humano & 279,3 & 288,46667 & 320,73333 & 388,5 & 524,9 \\
\hline \multicolumn{6}{|l|}{ Capital Estructural } \\
\hline \multicolumn{6}{|l|}{ Valores de la institución } \\
\hline sueldos y salarios & 915074,77 & 1044511 & 1121680 & 1382707,8 & 1759190,3 \\
\hline Incentivos a empleados & 47190,09 & 54832,16 & 79232,54 & 90384,69 & 100881,27 \\
\hline Colaboradores que fueron & & & & & \\
\hline evaluadas & 99 & 104 & 112 & 135 & 177 \\
\hline \multicolumn{6}{|l|}{ Total incentivos en seguros de } \\
\hline vida & 32270,21 & 37679,14 & 37708,01 & 41146,83 & 40310,78 \\
\hline Total de capital estructural & 994634,07 & 1137126,3 & 1238732,6 & 1514374,3 & 1900559,4 \\
\hline VALOR TOTAL CI. & 2303300,68 & 2662167,1 & 2908241 & 3793684,3 & 5306861,3 \\
\hline
\end{tabular}


De los datos obtenidos se puede evidenciar que la cooperativa a lo largo de los años estudiados ha realizado un avance significativo en educación a sus colaboradores y con una inversión creciente, pero para tener un impacto directo en sus colaboradores se sugiere:

1. Levantar información de los mismos colaboradores en los cuales identifiquen las áreas de mayor dificultad y que estas sean comunicadas a su jefe inmediato para realizar una socialización y puedan comunicar al departamento encargado para una retroalimentación eficiente.

2. Es necesario crear un departamento de educación-cooperativa que ayude a los empleados y mando jerárquico a planificar y desarrollar capacitaciones que cuenten con un presupuesto establecido en el POA anual de acuerdo a la necesidad.

3. Verificar por el área de recursos humanos que las capacitaciones que se vayan a realizar cuenten con los materiales adecuados, con las herramientas tecnológicas acorde a los temas a ser tratados y que sus tiempos sean adecuados para su cumplimiento.

4. Es de gran importancia contar con un sistema de evaluación tanto de ingreso como de retorno de las capacitaciones impartidas para poder calificar tanto la capacitación impartida como también como la vieron los diferentes funcionarios capacitados, para de esta manera tener retroalimentaciones de calidad y que no lleven a pérdidas económicos. 


\section{Diego Armando Coello-Paute; Juan Carlos Erazo-Álvarez; Cecilia Ivonne Narváez-Zurita; Juan Edmundo Álvarez-Gavilanes}

\section{Tabla 5.}

Capital humano, implementación de planes de capacitación basada en las dimensiones planteadas en los resultados obtenidos.

\section{$\square$ Capacitación Seguimiento y Evaluación}

Plan cronológico de inducción mensual

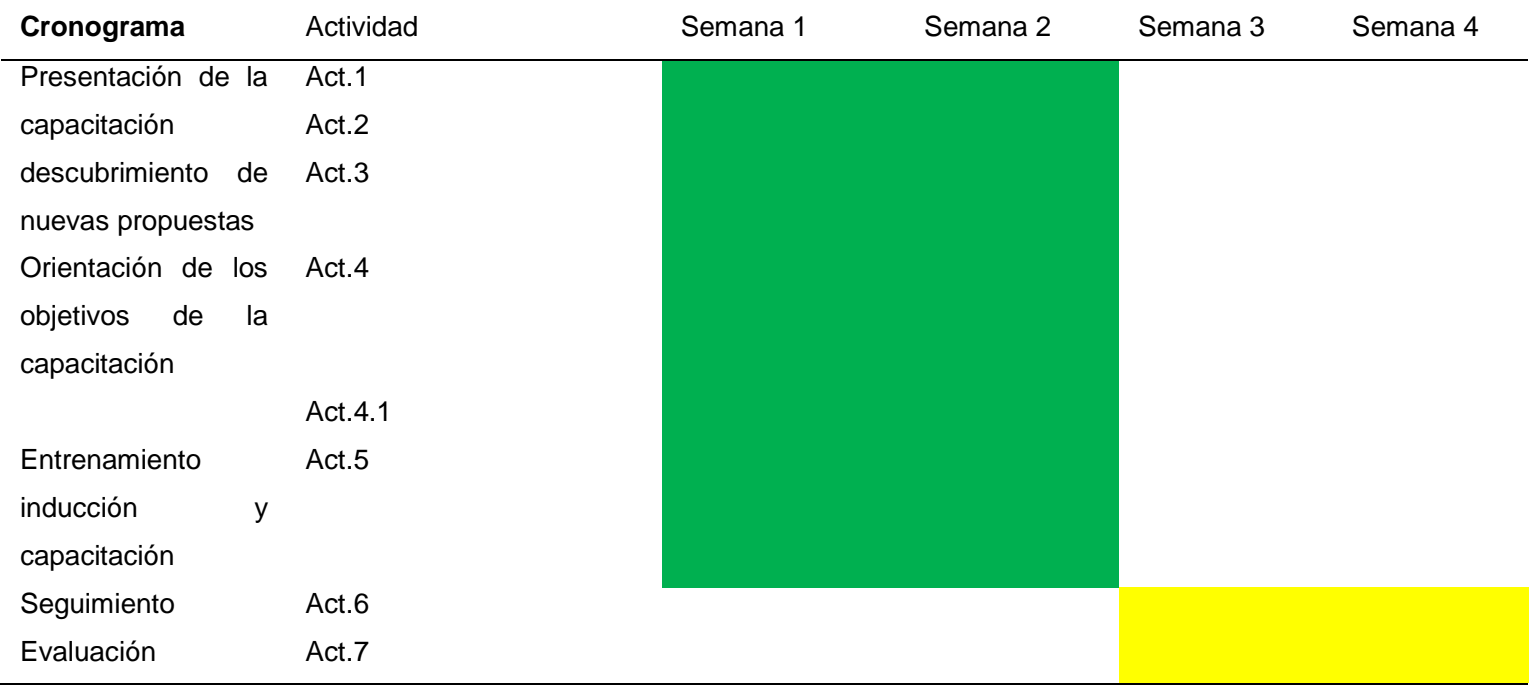

La cooperativa de ahorro y crédito Erco Ltda. cuenta con un plan de capacitaciones, sin embargo este no es de conocimiento de sus empleados, lo cual recae en la falta de preparación de herramientas tecnológicas y una planificación clara del impacto productivo que puede acarrear, por lo cual se plantea crear un departamento especializado en realizar planes de mejora, constatar los errores más comunes en los cuales se pueda determinar un presupuesto para ajustar los propósitos de la capacitación necesarios y que estos dinamicen un trabajo continuo y de alto rendimiento fortaleciendo no solo a los colaboradores sino también al consejo de administración, vigilancia y directivos en general, se debe realizar la recolección de información de las diferentes oficinas y departamentos usando la intranet como medio de comunicación para mostrar las falencias más comunes, este departamento capacitara y mostrara los resultados obtenidos mediante el aumento de productividad el mismo que debe ser superior al $80 \%$. 
Revista Arbitrada Interdisciplinaria KOINONIA

Año 2020. Vol V. №3. Especial: Administración

Hecho el depósito de Ley: FA2016000010

ISSN: 2542-3088

FUNDACIÓN KOINONIA (F.K). Santa Ana de Coro. Venezuela.

Diego Armando Coello-Paute; Juan Carlos Erazo-Álvarez; Cecilia Ivonne Narváez-Zurita; Juan Edmundo Álvarez-Gavilanes

\section{Tabla 6.}

Indicadores para medir el capital intelectual periodo 2019.

\begin{tabular}{|c|c|c|c|c|}
\hline Factores & Posición & & $\begin{array}{l}\text { Estabilidad } \\
\text { Liquidez }\end{array}$ & Eficiencia \\
\hline \multirow{3}{*}{ Mercado } & $\begin{array}{l}\text { Cartera de } \\
\text { crédito }\end{array}$ & 92295728,44 & Fondos disponibles/total depósitos corto plazo & $20,02 \%$ \\
\hline & & & Rentabilidad & \\
\hline & $\begin{array}{l}\text { Segmento de la } \\
\text { cooperativa }\end{array}$ & 1 & Resultado ejercicio/patrimonio promedio & $8,05 \%$ \\
\hline \multirow{3}{*}{ Internos } & & & Resultado ejercicio/activo promedio & $1,27 \%$ \\
\hline & $\begin{array}{l}\text { Aportación en } \\
\text { mercado } \\
\text { Aporte } \\
\text { profesional } \\
\text { Empleados con }\end{array}$ & 0,00021 & Precios en volumen y desarrollo & \\
\hline & $\begin{array}{l}\text { título profesional } \\
\text { Promedio de }\end{array}$ & 0,68 & Educación y formación & 12500,85 \\
\hline \multirow[t]{4}{*}{ Colaboradores } & edad enrolado & 34 & Inversión individual & 70,63 \\
\hline & & & Rotación de personal & 0,25 \\
\hline & & & Antigüedad Colaboradores en años & $>3$ \\
\hline & & & Gastos de operación/total activo & $5,31 \%$ \\
\hline \multirow{2}{*}{$\begin{array}{l}\text { Valor } \\
\text { Estructural }\end{array}$} & $\begin{array}{lr}\text { Costo de capital } \\
\text { Gastos re de } \\
\text { inversión capital }\end{array}$ & & costos de tecnología he inversión & \\
\hline & ajeno & 768166,03 & Tasa de interés pasiva plazo fijo & 4377028,78 \\
\hline \multirow{4}{*}{$\begin{array}{l}\text { Cifras } \\
\text { Financieras }\end{array}$} & Patrimonio neto & 20739991,02 & Tasa de interés pasiva ahorros & 524340,01 \\
\hline & & & Fondos disponibles & 9001404,46 \\
\hline & & & Tasa activa de créditos & 14103978 \\
\hline & & & Capital estructural activos & 3313918,97 \\
\hline
\end{tabular}

\section{CONCLUSIONES}

Ante los grandes cambios que tiene la cooperativa en la actualidad los funcionarios deben desarrollar nuevas habilidades como destrezas para poder adaptarse a estos cambios tecnológicos y de innovación, pero estas habilidades deben ser desarrolladas con una correcta inversión realizada por el mando jerárquico superior a todas sus alas del negocio. Los funcionarios están predispuestos a enfrentar nuevos retos pero que aquello conlleve a tener capacitaciones adecuadas y sean bien planificadas, que esto ayude a mejorar en su puesto de trabajo. La organización se preocupó por capacitar a sus funcionarios, pero estas capacitaciones no fueron de impacto para los oyentes las cuales muestran debilidades que en un corto plazo generan pérdidas de liquidez y de tiempo. 
Diego Armando Coello-Paute; Juan Carlos Erazo-Álvarez; Cecilia Ivonne Narváez-Zurita; Juan Edmundo Álvarez-Gavilanes

\section{FINANCIAMIENTO}

No monetario

\section{AGRADECIMIENTO}

A la cooperativa de ahorro y crédito Erco Ltda; por el apoyo prestado en el desarrollo de la investigación.

\section{REFERENCIAS CONSULTADAS}

Atencio-Cárdenas, E, \& González-Pertuz, B. (2007). Calidad de servicio en la editorial de la Universidad del Zulia (EDILUZ). [Quality of service in the publishing house of the University of Zulia (EDILUZ)]. Revista de Ciencias Sociales (Ve), XIII (1),172-186.

Bueno, E, Salmador, M, \& Merino, C. (2008). Génesis, concepto y desarrollo del capital intelectual en la economía del conocimiento: Una reflexión sobre el Modelo Intellectus y sus aplicaciones. [Genesis, concept and development of intellectual capital in the knowledge economy: A reflection on the Intellectus Model and its applications]. Estudios de Economía Aplicada, 26(2), 43-63.

Calderón, P. (2008). El capital intelectual como ventaja competitiva en las empresas del estado de Oaxaca. [Intellectual capital as a competitive advantage in companies in the state of Oaxaca]. Revista Nicolaita de Estudios Económicos, Vol. III, No. 2, 105-124.

Chiavenato, I. (2007). Administracion de los recursos humanos. [Human resource management]. Lons Angeles: Mc Graw- Hill//nteramericana Editores, S.A. de C.V. Recuperado de https://n9.cl/0xpa6

Chiavenato, I. (2009). Gestión del Talento Humano [Human Talent Management]. México DF. Mc Graw Hill. Recuperado de https://n9.cl/o2w6

Chiavenato, I. (2011). Administración de Recursos Humanos [Human resources management]. Santafé de Bogotá, Colombia. McGraw-Hill/ Interamericana Editores, S.A. de C.V. Recuperado de https://n9.cl/ged1

Cooperativa de Ahorro y Credito Erco. (2019). Reseña Historica de la Cooperativa de Ahorro y Credito Erco Ltda [Historical Review of Cooperativa de Ahorro y Credito Erco Ltda]. Cuenca: Erco. Recuperado de https://n9.cl/yi8p 
Diego Armando Coello-Paute; Juan Carlos Erazo-Álvarez; Cecilia Ivonne Narváez-Zurita; Juan Edmundo Álvarez-Gavilanes

Díaz, L. (2007). Gestión del conocimiento y del capital intelectual: una forma de migrar hacia empresas innovadoras, productivas y competitivas. [Knowledge and intellectual capital management: a way to migrate towards innovative, productive and competitive companies]. Revista Escuela de Administración de Negocios, (61),39-67

Duque-Oliva, E. (2005). Revisión del concepto de calidad del servicio y sus modelos de medición. [Review of the service quality concept and its measurement models]. INNOVAR. Revista de Ciencias Administrativas y Sociales, 15(25),64-80

Edvinsson, L. \& Malone, M.S. (1997). Intellectual Capital: Realizing Your Company's True Value by Finding Its Hidden Brainpower. Harper Business, New York.

Erazo-Álvarez, J. C., \& Narváez-Zurita, C. I. (2020). Medición y gestión del capital intelectual en la industria del cuero - calzado en Ecuador. [Measurement and management of intellectual capital in the leather industry - footwear in Ecuador]. Revista Arbitrada Interdisciplinaria Koinonía, 5(9), 437-467. http://dx.doi.org/10.35381/r.k.v5i9.662

Funes-Cataño, Y, \& Hernández-Garnica, C. (2001). Medición del valor del capital intelectual. [Intellectual Capital Measurement]. Contaduría y Administración, (203), 45-58

Ramón-Ochoa, M. d., Erazo-Álvarez, J. C., Narváez-Zurita, C. I., \& Matovelle-Romo, M. M. (2019). Gestión del capital intelectual en las cooperativas de ahorro y crédito de la ciudad de Loja aplicando el modelo Servqual [Management of intellectual capital in the credit unions of the city of Loja applying the Servqual model]. Visionario digital, 3(2.2), 284-308. https://doi.org/10.33262/visionariodigital.v3i2.2.644

Sánchez-Medina, A. J., \& Melián-González, A., \& Hormiga-Pérez, E. (2007). El concepto del capital intelectual y sus dimensiones. Investigaciones Europeas de Dirección y Economía de la Empresa, 13(2),97-111.

Superintendicia de Economia Popular y Solidaria. (2018). Boletin SEPS Numero 12 [SEPS Bulletin Number 12]. Recuperado de https://n9.cl/bam6. 
Revista Arbitrada Interdisciplinaria KOINONIA

Año 2020. Vol V. №3. Especial: Administración

Hecho el depósito de Ley: FA2016000010

ISSN: 2542-3088

FUNDACIÓN KOINONIA (F.K). Santa Ana de Coro. Venezuela.

Diego Armando Coello-Paute; Juan Carlos Erazo-Álvarez; Cecilia Ivonne Narváez-Zurita; Juan Edmundo Álvarez-Gavilanes

(02020 por los autores. Este artículo es de acceso abierto y distribuido según los términos y condiciones de la licencia Creative Commons Atribución-NoComercial-Compartirlgual 4.0 Internacional (CC BY-NC-SA 4.0) (https://creativecommons.org/licenses/by-nc-sa/4.0/). 